\title{
Challenges in the Successful Implementation of Data Warehouse
}

\author{
Dr. Bilal Ali Yaseen Alnassar \\ Management Information Systems, Faculty of Business and Finance \\ The World Islamic Sciences and Education University (WISE) \\ E-mail: bllnssr7575@gmail.com
}

Received: February 26, 2014

Accepted: May 1, 2014

Published: July 22, 2014

doi:10.5296/jmr.v6i3.5196

URL: http://dx.doi.org/10.5296/jmr.v6i3.5196

\begin{abstract}
Data warehouse refers to a database that gathers and stores data from various remote and heterogeneous sources of information. It is an Information System (IS) that extracts knowledge from the operational data stores of the business. It also provides information concerning suppliers, customers, markets and financial outcome. The present study provides an overview of data warehouse, a description of general data warehouse development process and highlights data warehouse challenges. The study also presents data warehouse success.
\end{abstract}

Keywords: Data warehouse, Information system, Data warehouse success 


\section{Introduction}

A data warehouse refers to an information system (IS) that extracts knowledge from the operational data stores of businesses. It is capable of providing information concerning suppliers, customers, markets and financial outcome. It also enables the organization to adapt to the current environment, learn from its past experiences and position itself for the future (Ganczarski, 2006). Moreover, a data warehouse comprises of data gathered from several sources, incorporated into a single repository and expanded by summarized information for analysis (Ester, Kriegel, Sander, Wimmer and Xu, 1998). Such repository enables businesses to gather, organize, interpret and use the information for their decision making (Groth, 2000; Wixom and Watson, 2001; Gupta and Mumick, 2005). It forms the basis for effective business intelligence solutions for firms striving to obtain competitive advantage (Chenoweth, Corral, and Demirkan, 2006). Data warehouse has been extensively utilized for data analysis to match the increasing maturity of the conventional transaction, in terms of stability and speed (Humphries, Hawkins, and Dy, 1999; Phipps and Davis, 2002; and Parida, 2005).

Current businesses are increasingly concentrated on obtaining competitive edge over its rivals and firms have acknowledged that the effective use of data is key to the next generation of business information technology (Kayworth, Chatterjee, and Sambamurthy, 2001; Carr, 2004). The strategic utilization of information technology has become a primary priority for every business as information technology facilitates the achievement of competitive as well as strategic advantage (Kearns and Lederer, 2000). In fact, technology that is capable of accessing, updating, organizing, and managing a significant volume of data have progressed over the past two decades (Sabherwal, Jeyaraj and Chowa, 2006; Biehl, 2007). In addition to this, majority of organizations have faced difficulties in processing a significant amount of data and transforming it into valuable information, until the emergence of data warehouse techniques. Consequently, there is an increasing data warehouse technology awareness within many organizations to be used to reinforce evidence-based decision making (Wixom and Watson, 2001; Gupta and Mumick, 2005). Data warehouse provides the optimum use of historical data to determine regularities and to enhance the decision making process.

\section{Overview of Data Warehouse}

Barry Devlin determined an analysis-oriented method to construct intelligent decision support systems called 'information warehouses' in the mid-1980s. By 1991, the first book concerning data warehouse entitled, "Building the Data Warehouse" was published by Inmon and he was acknowledged as the founder of data warehouse.

Data warehousing surfaced in the early 1990s as technology to support decision making that is capable of integrating data from several sources, and presenting and organizing data in a subject orientation. It soon became clear in the mid-1990s that developing an enterprise data warehouse was quite challenging and the concentration shifted to departmental data marts. In 1994, Ralph Kimball's first book "The Data Warehouse Toolkit" provided the design guidance on how to use data for analysis in an optimum way. Soon after, by the end of the 1990s, several organizations were employing data warehouses to help them in reaching 
strategic decisions concerning the required changes to retain their competitiveness in a dynamic environment (Heise, 2005).

More importantly, the concept of integrated data for management support is an old one as management information systems along with executive information systems have been utilized since the early 1970s (Shim et al., 2002). Nevertheless, the operational IT environment in major companies is quite heterogeneous because of the ever changing technologies (March, Hevner and Ram, 2000). Data is stored in legacy systems in different technologies and environments that range from PCs to mainframes (Robertson, 1997) and consequently, they are not capable of reinforcing management decision making process because they are not integrated. On the other hand, data warehouse integrates data and enhances access to accurate, consistent and timely data (Ang and Teo, 2000; and Ingham, 2000). Moreover, it facilitates effective decision support tools through the integration of corporate wide data into one repository from which users are able to run reports and conduct ad hoc data analysis (Meyer and Cannon, 1998). It makes use of the investments made in legacy systems, enabling business users to exploit informational assets (Counihan, Finnegan and Sammon, 2002). A data warehouse also reduces the cost, maximizes value added activities and enhances efficiency (Zeng, Chiang, and Yen, 2003).

\section{Data Warehouse Development Process}

Data warehousing is actually a system architecture rather than a software product/application (Agosta, 1999). Along the same line of contention, Manning (1999) is convinced that data warehouse was initially intended to be an architectural model for the data flow starting from operational systems and culminating in the decision support environments. The development of a data warehouse needs the integration of various tasks, components and coordinated effort of several individuals (Kimball, 2006). Authors such as Meyer and Cannon (1998) and Murtaza (1999) highlighted several data warehousing components and dimensions. The overall architecture of data warehouse is illustrated in Figure 1.1. The figure identifies the main components and the data flow throughout the system.

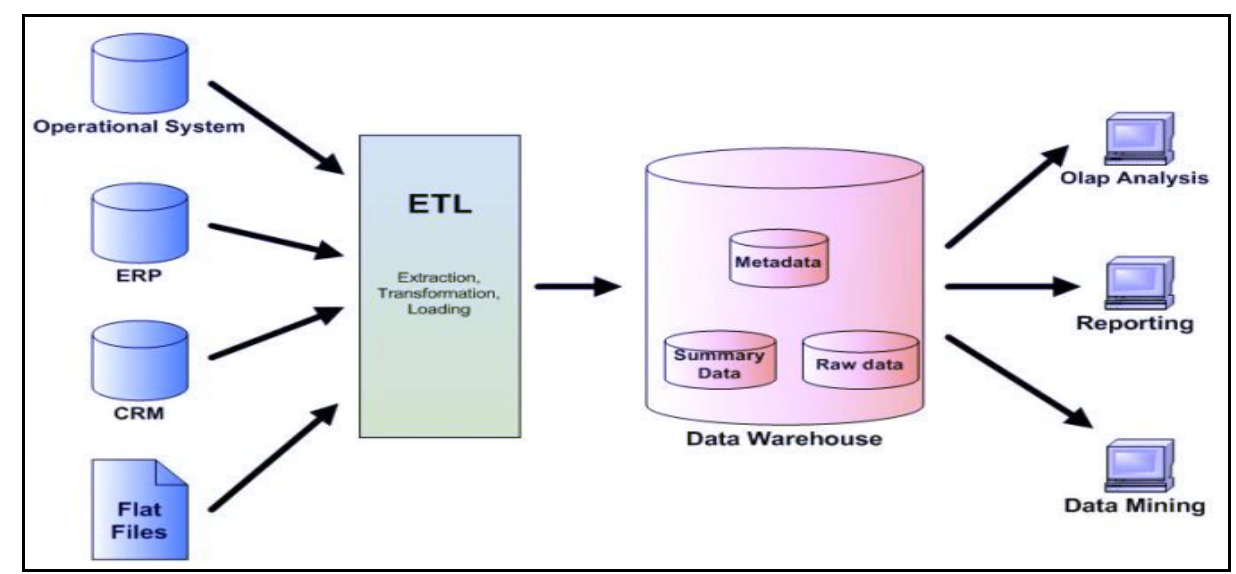

Figure 1. Architecture of a Data Warehouse (Humphries, Hawkins, \& Dy, 1999) 
A data warehouse can be divided into six main components (Meyer and Cannon, 1998) that are discussed below;

(i) Data Sourcing : Data warehouse development is characterized as complex and lengthy. First, this entails the identification of the information needs of the organization as this helps in determining the data needs that satisfies the information needs. The requirements are utilized for data model development, which offers the justification behind the development of data warehouse (Little and Gibson, 2003). Data sources are then determined in the transactional legacy systems, enterprise resource planning (ERP), e-commerce systems among others.

(ii) Data extraction and conversion : The next phase involves preparing and cleaning data. In this stage, source data is extracted, transformed into novel forms and loaded into the data warehouse environment. The complex issue of accurately identifying and combining databases becomes challenging as organizations realign their information infrastructure toward integrated data warehouses and decision support systems (Berndt and Satterfield, 2000). Manning (1999) contended that the extracting, cleaning and integrating data cost constitutes $60-80 \%$ of the total cost of a normal data warehousing project. One of the most difficult challenges faced in the process is ensuring superior quality data.

(iii) Data warehouse database :The center of the data warehousing system is occupied by good data management system. The provision of robust data management, scalability, high performance query process and services integration is conducted by the database server (Shahzad, 1999). Servers can be divided into two kinds namely Relational Database Management System (RDBMS) (Stephen, 1998; Vassiliadis, 2000b) and Multi-Dimensional Database (MDD) (Dinter, Sapia, Hofling, and Blaschka, 1998). The former type's implementation has its basis on a two-dimensional association of related data referred to as tables (Blaha, Premerlani and Hwa, 1994) while the latter type can be considered as a cube, wherein information is stocked high on the different cubic dimensions/axes (Buzydlowski, Song and Hassell, 1998; Niemi, 2003). The MDD is a technique that enables multi-part questions to be queried concerning the database. For instance, rather than a report on revenue forwarded by branch, MDD may report revenue by branch, and further sub-divide it in terms of product lines and region (Sullivan, 1996). However, RDBMS is superior to MDD when the huge data storage capacity is considered, along with portability issues/security. MDD is more extensively utilized for its instantaneous response, ease of implementation and Meta data integration (Shahzad, 1999).

(iv) Data warehouse administration : Data warehouse is riddled with several complex issues of administration that is distinct from transactional/decision support applications (Benander, Fadlalla and James, 2000). Data warehouse administration facilitates the smooth working o of the data warehouse environment. Owing to the several numbers of subject areas and the significant volume of historical data, a data warehouse needs considerable disk storage and extensive planning (Stephen, 1998). According to Roussopoulos (1998), data warehouse administration also provides query management and access control. Meanwhile other authors contended that it also imparts disaster recovery (Armstrong, 1997; Sen and Jacob, 1998), tool 
integration (Freude and Konigs, 2003), directory management and security (Stephen, 1998), request control (Agrawal, Abbadi, Singh and Yurek, 1997), capacity planning (Chaudhuri and Dayal, 1997), auditing of data usage (Stephen, 1998; Vassiliadis, 2000a) and administration of user (Chaudhuri and Dayal, 1997). Furthermore, data warehouse success depends on effective governance (Watson, Fuller and Ariyachandra, 2004).

(v) Business intelligence tools : After loading the data into the database, different access tools are utilized for the interaction of the end user. According to Gray and Watson (1998), access tools are defined as decision support tools that enable users to conduct an analysis of the information easily. As business intelligence tools are able to consolidate and analyze data for superior business decisions, they can often result in a competitive edge for the firm. The choice for the right end-user tool is crucial as the ease of use and functions range offered by the tools build the perceptions of the user concerning the data warehouse value and success. Additionally, data mining is the most widely used business intelligence tool in organizations. Data warehouse mining sheds a new light into value added business process, customer buying patterns, fraudulent activity and profitability of product. Furthermore, data mining can be defined as data analysis in large data bases to determine trends, similarities, and patterns in order to reinforce decision making of management (Zorn, Emanoil, Marshall and Panek, 1999).

(vi) Metadata : Metadata is another crucial data warehouse component. It is data concerning data - in other words, data that is used to provide description on other data and it indexes information and monitors its use (Sullivan, 1996). Metadata is invaluable in data warehouse for tool integration, data integration and change management. According to Sen (2004), there are two kinds of metadata namely back room metadata and front room metadata. The former guides the processes of extraction, cleaning and loading while the latter is more descriptive in that it assists in query tools and report writers. Metadata boosts the data warehouse users by assisting in their quest to acquire informational needs, data sources, data representation and access (Lee, Kim and Kim, 2001). In a related study, Lee et al. (2001) brought forward a metadata oriented data warehouse architecture comprising of seven components which are legacy system, extracting software, operational data store, data warehouse, data mart, application and metadata. They added that metadata should be integrated with data warehousing systems as without the former, the decision support of data warehouse may be controlled by the users.

From the above discussion of the six important components of data warehouse development process, it can be concluded that the process is complex as it needs various components and undergoes several phases. This complexity is noted at every phase, from the identification of data sources and data integration to system administration and business intelligence access tools. It can also be concluded that one of the top implementation challenges is the integration of the entire components needed for the design, transformation, storage, and management of data warehouse. The next section provides an overview of the challenges of data warehouse. 


\section{Data Warehouse Challenges}

Regardless of the many advantages offered by data warehouse, it is still deemed as a large, expensive and risky investment. Owing to its use of advanced hardware and software capabilities (e.g. symmetric multi-processing, ETL process), majority of firms have to employ external consultants as the required knowledge is not possessed in-house (Goeke, 2006). More importantly, data warehouse frequently calls for meaningful transformations in corporate culture. For instance, data warehouse reflects a marked deviation from traditional data processing and needs the organization's functional units to share data (Goeke, 2006) and this is quite challenging to achieve. Hence, upper management support for a data warehouse project is crucial and is deemed to be one of the significant predictors of successful implementation (Wixom and Watson, 2001; Watson and Ariyachandra, 2005).

Furthermore, despite the fact that data warehouse is a powerful tool that delivers information to users, creates competitive advantage and builds support for decision making (Berson, Smith, and Thearling, 1999; Groth, 2000; Inmon, 2005; Hwang and Xu, 2008), 20-50\% of these multi-million dollar projects fail to achieve the desired degrees of success (Conner, 2003; Wixom and Watson, 2001) with some abandoning the project altogether following the initial failure (Koch, 1999). A case in point is the most recent, high profile and visible failure of the Virtual Case File (VCF), which was commissioned by the FBI as a response to September 11, 2001 incident. It enables U.S. federal agents along with intelligence agencies to share information and to create a system that spot future attack by terrorists in the U.S. soil. The project cost over $\$ 175$ million (Goldstein, 2005). This failure has been addressed by Goldstein (2005). According to him, the failure was mainly attributed to the organizational structure, communication and implementation.

\section{Data Warehouse Success}

The effects brought about by the data warehouse systems are debatably difficult to gauge and to determine the success metrics (Hwang and Xu, 2008; Shin, 2003; Wixom and Watson, 2001; and Haley, 1997). The system may involve many users that range from top executives to end users, many applications such as data integration (ETL), data analysis (Cube), business intelligence, and data mining applications throughout the organization along with various capabilities and functionalities. The above system features and other matters previously discussed including high cost, process changes, and data warehouse systems complexity, indicate that existing models of the system success may not be enough to measure actual data warehouse success.

In the words of Chenoweth, Corral and Demirkan (2006, p.12), "The success of data warehouse depends on the interaction of technology and social context". Similarly, Hwang and $\mathrm{Xu}(2007,2008)$ stated that the success of data warehouse is a crucial issue for both research and practice. However, in reality, studies dedicated to the assessment of data warehousing practices and its critical factors are few and far between. In addition, Wixom and Watson (2001) stressed that data warehouses have distinct features that may shift the significance of factors applying to it. Meanwhile, Thomann and Wells (1999) provided three types of success aspects 
related to the system;

a. Economic success - the ability of the data warehouse to furnish information to those requiring it, in order to positively impact business.

b. Political success - the ability of the firm to promote awareness, access tools, knowledge and user skills to use the functions provided by the data warehouse system.

c. Technical success - the ability of the selected suitable technologies for the data warehouse tasks and its correct application.

Goldstein (2005)contended that the success of a data warehouse project is challenging owing to its complexity, size and various requirements. Some success strategies for this challenge include; to determine data warehouse project aims, to determine data warehouse quality drivers, to seek quality-driven data warehouse benefits, to establish data warehouse project success strategies, to guarantee success via active data warehouse project manager roles, to capitalize on the skills and strengths of data warehouse project management, and finally, to review the benefits of data warehouse. With regards to the reasons behind the failure of many organizations implementing data warehouse, Frolick and Lindsey (2003) reported them to be; weak sponsorship, and management support, issues of data quality, issues with end-user access tools, not enough funding, inadequate user involvement, ambiguous organizational politics and turnover of organizational personnel. Most of the failures are riddled with multiple reasons with the common being weak management support and inadequate user involvement (Frolick and Lindsey, 2003). Most of the reasons were organizational as opposed to technical with few exceptions.

Prior research also addressed the factors of data warehouse system success. In the present study, two sets of potential antecedent studies are highlighted. The first set of antecedents has its basis on the critical success factors (CSFs) or implementation success factors (ISFs) that could facilitate data warehouse success while the second set is adapted from the data warehouse success models. Specifically, Abu Ali and Abu Addose (2010) demonstrated the main critical success factors (CSFs) that influences the implementation of data warehouse systems. They conducted a case study on two organizations namely First American Corporation and Whirlpool Corporation to determine a general list of CSFs. Their findings showed that CSFs can be divided into five primary categories; organizational factors, environmental factors, project factors, technical factors, and educational factors.

\section{Conclusion and Future Research}

Based on the literature reviewed, data warehouse comprises of distinct features that separates it from other decision support applications. Data warehouse is also different from traditional operational systems. According to the data warehouse architecture and implementation discussed in the review, data warehouse has an enterprise wide influence on the organizational infrastructure. Literature has also addressed the difficulties of data warehouse implementation and calls for more in-depth studies to explore the factors that challenges data warehouse success. Future research is recommended to develop and validate a data warehouse system success model and to highlight the factors that govern and facilitate the effective implementation of data warehouse. Organizations can evidently benefit from an extensive 
understanding of the challenges which are significant to establishing a successful data warehouse systems implementation.

\section{References}

AbuAli, A. N., \& AbuAddose, H. Y. (2010). Data Warehouse Critical Success Factors. European Journal of Scientific Research, 42(2), 326-335.

Agrawal, D., El Abbadi, A., Singh, A., \& Yurek, T. (1997). Efficient view maintenance at data warehouses. Paper presented at the ACM SIGMOD international conference on Management of data, Tucson, Arizona, United States.

Ang, J., \& Teo, T. S. H. (2000). Management issues in data warehousing: insights from the Housing and Development Board. Decision Support Systems, 29(1), 11-20. http://dx.doi.org/10.1016/S0167-9236(99)00085-8

Armstrong, R. (1997). Data Warehousing: Dealing with the Growing Pains. Paper presented at the Thirteenth International Conference on Data Engineering, Birmingham UK.

Benander, A. B., Fadlalla, A., \& James, G. (2000). Data Warehouse Administration and Management. Information Systems Management, 17(1), 71-80. http://dx.doi.org/10.1201/1078/43190.17.1.20000101/31217.10

Berndt, D. J., \& Satterfield, R. K. (2000). Customer and household matching: Resolving entity identity in data warehouses. Proc Spie Int Soc Opt Eng, 4057, 173-180.

Berson, A., Smith, S., \& Thearling, K. (1999). Building Data Mining Applications for CRM: McGraw-Hill Professional.

Biehl, M. (2007). Success factors for implementing global information systems. Communications of the ACM, 50(1), 52-58. http://dx.doi.org/10.1145/1188913.1188917

Blaha, M., Premerlani, W., \& Hwa, S. (1994). Converting OO models into RDBMS schema. Software, IEEE, 11(3), 28-39. http://dx.doi.org/10.1109/52.281715

Buzydlowski, J. W., Song, I. Y., \& Hassell, L. (1998). A framework for object-oriented on-line analytic processing. Paper presented at the 1st ACM international workshop on Data warehousing and OLAP. http://dx.doi.org/10.1145/294260.294264

Carr, N. G. (2004). IT Doesn't Matter. IEEE Engineering Management Review, 32(1), 24-32. http://dx.doi.org/10.1109/EMR.2004.25006

Chaudhuri, S., \& Dayal, U. (1997). An overview of data warehousing and OLAP technology. ACM SIGMOD Record, 26(1), 65-74. http://dx.doi.org/10.1145/248603.248616

Chenoweth, T., Corral, K., \& Demirkan, H. (2006). Seven key interventions for data warehouse success. Communications of the ACM, 49(1), 114-119. http://dx.doi.org/10.1145/1107458.1107464

Conner, D. (2003). Data warehouse failures commonplace. Network World, 20(3), 24. 
Counihan, A., Finnegan, P., \& Sammon, D. (2002). Towards a framework for evaluating investments in data warehousing. Information Systems Journal, 12(4), 321-338. http://dx.doi.org/10.1046/j.1365-2575.2002.00134.x

Dinter, B., Sapia, C., Höfling, G., \& Blaschka, M. (1998). The OLAP market: state of the art and research issues. Paper presented at the $1 \mathrm{st}$ ACM international workshop on Data warehousing and OLAP. http://dx.doi.org/10.1145/294260.294268

Ester, M., Kriegel, H. P., Sander, J., Wimmer, M., \& Xu, X. (1998). Incremental Clustering for Mining in a Data Warehousing Environment. Proceedings of the 24rd International Conference on Very Large Data Bases, 323-333.

Frolick, M. N., \& Lindsey, K. (2003). Critical factors for data warehouse failure. Journal of Data Warehousing, 8(1), 48-54.

Ganczarski, J. Z. (2006). Critical implementation factors in data warehouse implementations in Canadian financial institutions: Qualitative expanded study. Unpublished Ph.D., Northcentral University, United States, Arizona.

Goeke, R. J. (2006). An examination of the effects of experience, expertise, and perceived flexibility on data warehouse use. Unpublished $\mathrm{PhD}$, Kent State University

Goldstein, H. (2005). Who killed the virtual case file? IEEE SPECTRUM, 42(8), 18.

Groth, R. (2000). Data mining: building competitive advantage: Prentice Hall PTR Upper Saddle River, NJ, USA.

Gupta, H., \& Mumick, I. S. (2005). Selection of views to materialize in a data warehouse. European Journal of Information Systems,34(2),12-17.

Haley, B. J. (1997). Implementing the decision support infrastructure: Key success factors in data warehousing. Unpublished Ph.D., University of Georgia, United States, Georgia.

Heise, D. L. (2005). Data Warehousing and Decision Making in Higher Education in the United States. Unpublished Ph.D., Andrews University.

Humphries, M., Hawkins, M. W., \& Dy, M. C. (1999). Data Warehousing: Architecture and Implementation: Prentice Hall PTR.

Hwang, M. I., \& Xu, H. (2008). A Structural Model Of Data Warehousing Success. Journal of Computer Information Systems, 49(1).

Ingham, J. (2000). Data warehousing: a tool for the outcomes assessment process. Education, IEEE Transactions on, 43(2), 132-136. http://dx.doi.org/10.1109/13.848064

Inmon, W. H. (2005). Building the data warehouse (4th ed.): John Wiley \& Sons, Inc. New York, NY, USA.

Kayworth, T. R., Chatterjee, D., \& Sambamurthy, V. (2001). Theoretical Justification for IT Infrastructure Investments. Information Resources Management Journal, 14(3), 5-14. http://dx.doi.org/10.4018/irmj.2001070101 
Kearns, G. S., \& Lederer, A. L. (2000). The effect of strategic alignment on the use of IS-based resources for competitive advantage. Journal of Strategic Information Systems, 9(4), 265-293. http://dx.doi.org/10.1016/S0963-8687(00)00049-4

Kimball, R. (2006). The data warehouse toolkit (3ed): Wiley-India.

Koch, C. (1999, 25 January). The Middle Ground. CIO Magazine.

Lee, H., Kim, T., \& Kim, J. (2001). A Metadata Oriented Architecture for Building Datawarehouse. Journal of Database Management, 12(4), 15-25. http://dx.doi.org/10.4018/jdm.2001100102

Little, R. G., \& Gibson, M. L. (2003). Perceived influences on implementing data warehousing. IEEE Transactions on Software Engineering, 29(4), 290-296. http://dx.doi.org/10.1109/TSE.2003.1191794

Manning, I. T. (1999). Data Warehousing-Adopting an Architectural View, and Maximizing Cost Benefits. The Ultimate Guide to Build Business Intelligence, 27-32.

March, S., Hevner, A., \& Ram, S. (2000). Research Commentary: An Agenda for Information Technology Research in Heterogeneous and Distributed Environments. Information Systems Research, 11(4), 327-341. http://dx.doi.org/10.1287/isre.11.4.327.11873

Meyer, D., \& Cannon, C. (1998). Building a Better Data Warehouse: Prentice Hall Upper Saddle River, NJ.

Murtaza, A. H. (1999). A Framework for Developing Enterprise Data Warehouses. Information Systems Management, 21-26. http://dx.doi.org/10.1201/1078/43186.15.4.19980901/31147.4

Parida, R. (2005). Principles and Implementation of Datawarehousing: Firewall Media.

Phipps, C., \& Davis, K. (2002). Automating Data Warehouse Conceptual Schema Design and Evaluation. Paper presented at the International Workshop on Design and Management of Data Warehouses, Canada.

Robertson, P. (1997). Integrating legacy systems with modern corporate applications. Communications of the ACM, 40(5), 39-46. http://dx.doi.org/10.1145/253769.253785

Sabherwal, R., Jeyaraj, A., \& Chowa, C. (2006). Information System Success: Individual and Organizational Determinants. Management Science, 52(12), 1849-1864. http://dx.doi.org/10.1287/mnsc.1060.0583

Sen, A. (2004). Metadata management: past, present and future. Decision Support Systems, 37(1), 151-173. http://dx.doi.org/10.1016/S0167-9236(02)00208-7

Shahzad, M. A. (1999). Data warehousing with Oracle. Paper presented at the SPIE - The International Society for Optical Engineering.

Shim, J. P., Warkentin, M., Courtney, J. F., et al. (2002). Past, present, and future of decision support technology. Decision Support Systems, 33(2), 111-126. 
http://dx.doi.org/10.1016/S0167-9236(01)00139-7

Shin, B. (2003). An Exploratory Investigation of System Success Factors in Data Warehousing. Journal of the Association for Information Systems, 4(2), 141-170.

Stephen, R. G. (1998). Building the data warehouse. Commun. ACM, 41(9), 52-60. http://dx.doi.org/10.1145/285070.285080

Sullivan, O. (1996). Data Warehousing-without the Warehouse. ABA Banking Journal, 88(12).

Thomann, J., \& Wells, D. (1999). Data Warehouse Quality Management. Paper presented at the Data Warehousing Institute's 4th Annual Implementation Conference, Anaheim, CA.

Timo Niemi, L. H. K. J. (2003). Multidimensional Data Model and Query Language for Informetrics. Journal of the American Society for Information Science and Technology, 54(10), 939-951. http://dx.doi.org/10.1002/asi.10290

Vassiliadis, P. (2000a). Gulliver in the land of data warehousing: practical experiences and observations of a researcher. Paper presented at the International Workshop on Design and Management of Data Warehouses (DMDW'2000), Stockholm, Sweden.

Vassiliadis, P. (2000b). Data Warehouse Modeling and Quality Issues. Unpublished PhD, National Technical University of Athens, Athens.

wang, M. I., \& Xu, H. (2007). The Effect of Implementation Factors on Data Warehousing Success: An Exploratory Study. Journal of Information, Information Technology, and Organizations, 2 .

Watson, H. J., \& Ariyachandra, T. (2005). Data warehouse architectures: factors in the selection decision and the success of the architectures. University of Georgia, USA.

Watson, H. J., Fuller, C., \& Ariyachandra, T. (2004). Data warehouse governance: best practices at Blue Cross and Blue Shield of North Carolina. Decision Support Systems, 38(3), 435-450. http://dx.doi.org/10.1016/j.dss.2003.06.001

Wixom, B. H., \& Watson, H. J. (2001). An Empirical Investigation of the Factors Affecting Data Warehousing Success. MIS Quarterly, 25(1), 17-41. http://dx.doi.org/10.2307/3250957

Zeng, Y., Chiang, R. H. L., \& Yen, D. C. (2003). Enterprise integration with advanced information technologies: ERP and data warehousing. Information Management \& Computer Security, 11(3), 115-122. http://dx.doi.org/10.1108/09685220310480390

Zorn, P., Emanoil, M., Marshall, L., \& Panek, M. (1999). Mining meets the Web. Online, 23(5), 16-28. 